\title{
Avaliação de Políticas Públicas: Desafios e Potencialidades para a Psicologia
}

\author{
Gislayne Cristina Figueiredo ${ }^{1}$ \\ ${ }^{1}$ Universidade Federal do Mato Grosso, MT, Brasil.
}

\begin{abstract}
Resumo: Embora a presença da psicologia no campo das políticas públicas sociais já esteja em processo de consolidação, a inserção do psicólogo na avaliação dessas políticas é ainda recente e a produção acadêmica sobre essa temática praticamente inexiste. Neste artigo, discutimos a atuação do psicólogo na avaliação de políticas sociais e serviços, tendo como base o trabalho desenvolvido por esse profissional no Ministério Público de São Paulo. Considera-se que as políticas sociais - e as instituições que as efetivam - são ambivalentes, posto que visam atender as necessidades básicas dos cidadãos, mas também atuam como mecanismos de controle e apaziguamento dos conflitos sociais. Dessa forma, nos processos avaliativos, o psicólogo deve ter como foco os processos de subjetivação engendrados pelas políticas sociais e pelas instituições que as consubstanciam - seja nas pessoas atendidas, nos próprios efetivadores da política (técnicos e demais funcionários), nas comunidades onde estão inseridas, nos grupos sociais que sentem seus efeitos e na sociedade como um todo -, evidenciando assim a dimensão subjetiva dos fenômenos sociais e concorrendo para a efetivação de políticas e serviços que amparem as reais necessidades dos atendidos e que contribuam com a transformação social e com a produção de subjetividades emancipadas.
\end{abstract}

Palavras-chave: Psicologia social, Psicologia jurídica, Avaliação de políticas públicas, Ministério Público Estadual.

\section{Evaluation of Public Policies: Challenges and Potentialities for Psychology}

\begin{abstract}
Although the presence of psychology in the field of social public policies is already in the process of consolidation, the insertion of this professional in the evaluation of these policies is still recent and academic production on this topic is practically non-existent. In this article, we discuss the performance of psychologist in evaluating social policies and services, based on the work developed by this professional in the Public Prosecution Office of São Paulo. Social policies and the institutions that enforce them - are considered as ambivalent, since they aim to meet the basic needs of citizens but can act as mechanisms for control and appeasement of social conflicts. Thus, in the evaluation processes, the psychologist must focus on the processes of subjectivation engendered by social policies and the institutions that embody them - be it in the people assisted, in the policy enforcers themselves (technicians and other employees), in the communities where they are inserted, in the social groups that feel their effects, and in society as a whole-, thus evidencing the subjective dimension of social phenomena and running for the implementation of policies and services that meet the real needs of those they serve and that contribute to social transformation and to the production of emancipated subjectivities.
\end{abstract}

Keywords: Social psychology, Legal psychology, Evaluation of public policies, State Public Prosecutor. 


\title{
Evaluación de Políticas Publicas: Desafíos y Potencialidades para la Psicología
}

\begin{abstract}
Resumen: Aunque la presencia de la psicología en el campo de las políticas públicas sociales ya está en proceso de consolidación, la inserción de los psicólogos en la evaluación de estas políticas es aún reciente, y la producción académica sobre este tema es prácticamente inexistente. En este artículo, discutimos el rol del psicólogo en la evaluación de políticas y servicios sociales, en base al trabajo desarrollado por este profesional en el Ministerio Público de São Paulo. Las políticas sociales, y las instituciones que las implementan, se consideran ambivalentes, ya que visan satisfacer las necesidades básicas de los ciudadanos, pero pueden actuar como mecanismos para controlar y apaciguar los conflictos sociales. Por lo tanto, en los procesos de evaluación, el psicólogo debe enfocarse en los procesos de subjetivación engendrados por las políticas sociales y las instituciones que las sustentan, ya sea en las personas atendidas, en los mismos formuladores de políticas (técnicos y otros empleados), en las comunidades donde operan, en los grupos sociales que sienten sus efectos y en la sociedad en su conjunto, destacando así la dimensión subjetiva de los fenómenos sociales y contribuyendo a la implementación de políticas y servicios que satisfagan las necesidades reales de aquellos atendidos y que contribuyan a la transformación y producción social y a la producción de subjetividades emancipadas.
\end{abstract}

Palabras clave: Psicología social, Psicología legal, Evaluación de políticas públicas, Ministerio Público del Estado.

\section{Introdução}

A presença de psicólogos na área de políticas públicas sociais tem conhecido um movimento de crescimento significativo desde os anos 1990. Essa ampliação não se deu apenas em virtude do incremento no número de psicólogos inseridos nessas políticas, mas também devido à ampliação nas modalidades de trabalho realizado por esses profissionais, que passaram a incluir tipos de atuação consideradas emergentes ou não tradicionais para a psicologia, como as atividades de gestão (formulação, implementação, avaliação e acompanhamento de políticas públicas) e as de coordenação de serviços e instituições.

Se a produção teórico-metodológica a respeito do trabalho da psicologia no âmbito das políticas públicas já conta com um acúmulo considerável, pouco ou quase nada foi produzido sobre a atuação da psicologia em atividades de gestão de políticas ou serviços sociais. Dessa forma, restam questionamentos sobre a natureza e as características da intervenção do psicólogo nessa área, inclusive sobre qual contribuição específica o olhar da psicologia pode aportar para as atividades técnico-gerenciais de instituições e para a formulação e implementação das políticas sociais.

Assinalamos que políticas públicas e políticas sociais se referem a campos que, se comportam algumas interfaces, são consideravelmente diferentes.

Em consonância com Ortuso e Giovanni (2015, p. 766), compreende-se que o termo "políticas sociais" se refere "a um conceito mais amplo, de sistema de proteção social, entendido basicamente como um conjunto de formas - as vezes mais, as vezes menos institucionalizadas - que as sociedades constituem para proteger parte ou a totalidade de seus membros". Engloba a provisão de políticas e de serviços nas áreas de seguridade social, de renda, assistência pública, saúde, bem-estar e moradia (Giovanni \& Nogueira, 2015), efetivadas por entes públicos ou de direito privado, como Organizações Não Governamentais (ONG), Organizações da Sociedade Civil de Interesse Público (Oscip), ou entidades de cunho filantrópico' ${ }^{1}$.

Já política pública se refere a "uma configuração específica de relações de poder-uma configuração institucionalizada, recorrente e estruturada - mediante a

\footnotetext{
${ }^{1}$ No presente artigo, considerando que as normativas da área social incluem as entidades da sociedade civil e filantrópicas dentro do Sistema de Garantia de Direitos, considerando-as como prestadoras de um serviço público delegado, utilizaremos os termos "políticas públicas sociais" e "políticas sociais" para nos referirmos às ações efetivadas tanto por entes públicos quanto por privados na área de seguridade social.
} 
qual se constitui uma probabilidade de ação coletiva" (Giovanni \& Nogueira, 2015, p. 20), dizendo respeito às ações efetivadas pelos entes públicos, não necessariamente circunscritas à área social.

O presente artigo objetiva discutir a presença da psicologia na área das políticas sociais, tendo como recorte sua atuação no processo avaliativo dessas políticas. Para tanto, parte de um relato de experiência de atuação no Ministério Público do Estado de São Paulo, instituição na qual os psicólogos têm como atribuição principal avaliar serviços e instituições, conselhos de participação da sociedade civil, políticas públicas municipais e estaduais, e planos municipais e estaduais ligados às políticas sociais e ao Sistema de Garantia de Direitos.

Para compreender as potencialidades e dificuldades dessa atuação, partimos da premissa de que o contato da psicologia com o campo das políticas públicas não pode ser dissociado de uma série de transformações epistemológicas e ético-políticas pelas quais a profissão tem passado, que levaram a uma mudança na compreensão acerca do fenômeno psicológico e seus condicionantes.

Se mudanças ocorridas na psicologia contribuíram para sua inserção no campo das políticas sociais, dialeticamente, o contato com essas últimas aprofundou as transformações, levando a psicologia a desnaturalizar-se como campo do saber, a perceber sua atuação como política e a questionar seu papel como produtora de subjetividade (Benevides, 2005; Figueiredo, 2019; Silva \& Carvalhaes, 2016).

Além disso, a ampliação da inserção da psicologia nesse campo também contribui com uma modificação na compreensão acerca das políticas públicas e do modo de efetivá-las, chamando a atenção para a "dimensão subjetiva presente no campo das políticas públicas” (Gonçalves, 2010, p. 17), elemento até então pouco considerado pelos efetivadores e pelos estudiosos dessas políticas.

Neste trabalho, com o intuito de organizar nossa reflexão a respeito da atuação do psicólogo como avaliador de políticas públicas sociais, após uma breve contextualização acerca da inserção da psicologia nesse campo, abordaremos três aspectos diferentes dessa atuação, a saber: inicialmente, discorreremos sobre a atuação do psicólogo na avaliação de políticas públicas sociais no Ministério Público de São Paulo; em seguida, passaremos a discutir a atuação da psicologia no campo de avaliação de políticas e as contribuições específicas que pode aportar a esse campo; e, por fim, teceremos considerações sobre os desafios e potencialidades dessa atuação.

\section{A psicologia e as políticas públicas sociais}

As políticas públicas sociais têm como objetivo explícito atender as necessidades básicas dos cidadãos, visando minorar os efeitos do processo de pauperização da massa dos trabalhadores, fenômeno decorrente das relações desiguais existentes em nossa sociedade (Oliveira, 2017). Podem ser definidas como estratégias do Estado para responder à "Questão Social", conceituada como "o conjunto de problemas sociais, políticos e econômicos postos pela emergência da classe trabalhadora nos marcos de consolidação do Modo de Produção Capitalista, ou seja, é a manifestação, no cotidiano, da contradição capital-trabalho" (Oliveira \& Costa, 2018, p. 33).

Como construções histórico-sociais, as políticas públicas sociais são ambivalentes e contraditórias, posto que resultam das lutas, pressões e demandas das classes trabalhadoras pela garantia de seus direitos e por melhores condições de vida, ao mesmo tempo em que servem como mecanismo de apaziguamento e regulação dos conflitos sociais (Gonçalves, 2010; Oliveira \& Costa, 2018; Yamamoto, 2009).

Cabe destacar não só o caráter ambivalente das políticas públicas sociais - que de um lado visam garantir os direitos e, por outro, acabam servindo como forma de controle e de normatização da população -, mas também o caráter de disputa e de construção histórico-social do que pode ser considerado como direito, isto é, aquilo que se deve assegurar a todos os membros de uma determinada sociedade (Gonçalves, 2010; Silva \& Carvalhaes, 2016).

É necessário assinalar que além de serem contraditórias, como são fruto de lutas e de interesses por vezes antagônicos, as políticas públicas sociais passam por períodos de avanços e de retrocessos, ou seja, períodos nos quais os direitos se ampliam ou se retraem (Gonçalves, 2010).

No cenário atual, percebe-se uma disputa entre uma compreensão das políticas sociais como forma de garantia dos direitos que são inerentes ao ser humano, e uma compreensão delas como mercadoria, a ser provida segundo uma lógica meritocrática, via mercado, e com uma participação mínima do Estado (Cruz \& Guareschi, 2012; Gonçalves, 2010; Oliveira, 2017). 
A incorporação dos psicólogos no campo das políticas públicas, em seus mais variados setores, coincide com um momento histórico no qual as forças democráticas conseguem fazer avançar, no campo político, a organização de um Estado mais permeável às demandas sociais, contrapondo um projeto de sociedade mais popular ao projeto marcadamente classista e excludente vigente durante a ditadura militar (Conselho Federal de Psicologia [CFP], 2019).

Importante salientar que a psicologia nunca esteve ausente das políticas públicas sociais, haja vista que desde os primórdios da profissão no país, ela se fez presente em áreas como educação, saúde, jurídica, entre outras. A atuação nesses campos, no entanto, se caracterizava por dois aspectos principais: era numericamente inexpressiva, pois a atividade por excelência da psicologia era a clínica; e se dava de forma secundária, pois nesses espaços a psicologia assumia uma atuação subsidiária à das outras profissões (Cordeiro, Svartman, \& Souza, 2018; Gonçalves, 2010).

Com a reabertura política, nos anos 1990, ocorre um movimento de redescoberta e de consolidação das políticas públicas como espaço de atuação legítimo para a psicologia. Nesse sentido, Miron e Guareschi (2017, p. 358) se referem ao campo de políticas públicas como o "velho novo campo de atuação" da psicologia.

O crescimento significativo no número de psicólogos atuando na área de políticas públicas sociais se dá, por um lado, em função de transformações epistemológicas e ético-políticas na própria profissão, em um movimento de questionamento das concepções até então vigentes na psicologia com relação ao fenômeno psicológico e suas determinações; e, por outro, em função da necessidade de ampliação dos postos de trabalho para uma profissão com um mercado já saturado (Macedo \& Dimenstein, 2012; Miron \& Guareschi, 2017; Oliveira \& Amorim, 2012).

A estruturação do Sistema Único de Assistência Social (SUAS), com a previsão da presença do psicólogo em todas as equipes técnicas dos serviços desse Sistema, pode ser considerada como um marco dessa inserção, posto que a entrada massiva dos psicólogos na área de assistência social produziu uma série de questionamentos não só quanto aos modelos de intervenção utilizados pela psicologia, mas também com relação aos compromissos que essa atuação evidencia (Cordeiro et al., 2018; Miron \& Guareschi, 2017).
Compreender as práticas adotadas pela psicologia no âmbito das políticas públicas sociais demanda conhecer as diferentes bases epistemológicas, ontológicas e teórico-metodológicas que embasam essa atuação.

Silva e Carvalhaes (2016) assinalam duas diferentes posições, do ponto de vista epistemológico e ontológico, assumidas pelas diversas linhas de pensamento na psicologia: uma que compreende a subjetividade como decorrente de processos individuais e internos; e outra que considera a subjetividade como processual e inseparável das condições concretas e materiais de existência.

Essas duas posições produzem práticas divergentes e, geralmente, antagônicas. Nesse sentido, Miron e Guareschi (2017, p. 358) contrapõem duas formas opostas de intervenção da psicologia junto às políticas públicas sociais: uma em que a psicologia opera como "tecnologia de equilíbrio social", alinhada com o Estado e cumprindo o papel de amortizador das contradições sociais; e uma atuação que de fato contribui para a transformação social e para a garantia de direitos da população.

A persistência de uma atuação que considera a subjetividade como algo estritamente individual tem sido assinalada como geradora de uma série de conflitos e desafios na atuação da psicologia no campo das políticas públicas sociais. Críticas têm sido tecidas ao enfoque a-histórico muitas vezes adotado, à ausência de clareza acerca da atuação da psicologia nessas políticas, à individualização, psicologização e patologização de questões que são sócio-histórica e culturalmente condicionadas; à adoção de uma postura que culpabiliza a família ("familismo"); à postura adaptativa e normalizadora; à contribuição com processos de controle social e de manutenção de uma ordem excludente; à posição elitista assumida por muitos profissionais (Cordeiro et al., 2018; Gonçalves, 2010; Miron \& Guareschi, 2017; Oliveira, 2017; Silva \& Carvalhaes, 2016; Yamamoto \& Oliveira, 2010).

Em contrapartida, uma compreensão da subjetividade que supere a dicotomia individual/social e que tenha em conta os fatores históricos, sociais e culturais como elementos constituintes das subjetividades, pode levar a uma prática que efetive o compromisso social da psicologia, que contribua com a produção de subjetividades emancipadas - nas quais as pessoas sejam sujeitos de sua própria história - e que promova a transformação social (Benevides, 2005; Silva \& Carvalhaes, 2016). 
Nesse sentido, é importante frisar o aspecto de potência presente em uma atuação crítica e comprometida com a defesa, ampliação e garantia dos direitos, visando o incremento da autonomia da população atendida. Esta atuação pode não só trazer para o primeiro plano a questão da subjetividade que é engendrada pelas políticas públicas e oferecer um serviço qualificado e mais efetivo para as pessoas atendidas, mas também promover transformações para próprio campo de conhecimento e prática da psicologia (Cordeiro et al., 2018; Silva \& Carvalhaes, 2016).

\section{A atuação da psicologia no Ministério Público do Estado de São Paulo}

Realizar avaliações de políticas públicas sociais e de serviços é a principal função exercida pelos psicólogos no Ministério Público do Estado de São Paulo (MPSP). A maior parte dos profissionais de psicologia dessa instituição está lotada no Núcleo de Apoio Técnico Psicossocial (NAT) ${ }^{2}$, que tem como função assessorar os promotores no que diz respeito a:

- avaliar políticas públicas sociais, planos, programas e projetos relativos às matérias de ... Psicologia dos órgãos de Administração Direta ou Indireta do Estado e dos Municípios, organizações da sociedade civil, movimentos sociais e Conselhos de Direitos, sugerindo medidas para implementação ou reordenamento das políticas já existentes;

- planejar, executar e avaliar pesquisas dos órgãos de Administração Direta ou Indireta do Estado e dos Municípios, organizações da sociedade civil, movimentos sociais e Conselhos de Direitos que possam contribuir para a análise da realidade social e para subsidiar ações e decisões no âmbito do Ministério Público do Estado de São Paulo; . . . (MPSP \& Procuradoria-Geral de Justiça, 2012).

Sua atuação, que em geral é realizada em conjunto com o assistente social, consiste em realizar a avaliação de serviços como instituições de acolhimento para crianças e adolescentes (Saica), instituições de acolhimento para idosos (ILPI), serviços de atendimento a mulheres vítimas de violência, serviços de medidas socioeducativas, instituições do Sistema de Garantia de Direitos (SGD), instituições e serviços do Sistema Único de Assistência Social (SUAS), do Sistema Único de Saúde (SUS) e do sistema de educação, de Conselhos Municipais e estadual de garantia de direitos, entre outros. Essas avaliações são realizadas tanto em instituições públicas quanto em entidades privadas com fins públicos e de interesse social.

Além de serviços específicos, o psicólogo realiza avaliações das políticas municipais e estadual, das redes intrasetoriais e intersetoriais, dos planos municipais e estadual das várias políticas, bem como acompanhamento de conferências e outros fóruns de participação popular.

Em casos nos quais há determinação do promotor, o psicólogo também atua na apuração de denúncias de violação de direitos ocorridas em espaçosinstitucionais.

Para subsidiar a coleta de dados e as intervenções realizadas, o psicólogo do Ministério Público dispõe de uma variedade de instrumentos cujo uso é consolidado pela profissão, entre os quais podemos citar:

- Análise documental: pode incluir tanto a análise da legislação, das regulamentações e dos parâmetros da política, quanto dos documentos do serviço avaliado. Estes últimos podem ser desde documentos produzidos por terceiros, como o processo judicial ou notícias veiculadas na mídia sobre o serviço, até os produzidos diretamente pela instituição, como regimentos, estatutos, regras internas, Projetos Pedagógicos e prontuários dos indivíduos e famílias atendidas;

- Visitas de inspeção e observação: esses são os dois principais instrumentos utilizados pelo psicólogo no Ministério Público de São Paulo e, em geral, são efetivados simultaneamente. As visitas podem ocorrer mediante aviso prévio à instituição visitada, ou não. Nessas visitas, são realizadas observações quanto ao funcionamento institucional e da rede, o ambiente, as condições de trabalho, asinterações entreprofissionais, entre profissionais e atendidos, e entre os atendidos. Durante as visitas também podem ocorrer entrevistas e atividades grupais propostas pelo psicólogo, dependendo da necessidade sentida por esse profissional;

\footnotetext{
${ }^{2}$ De acordo com levantamento realizado por Figueiredo (2019), dos 32 psicólogos atuando na instituição, 25 estão lotados no Núcleo de Apoio Técnico Psicossocial, 3 estão lotados em Grupos de Atuação Especial (Educação e Enfrentamento à Violência Doméstica), e 4 estão lotados no serviço de saúde, realizando um atendimento de cunho mais clínico a promotores e funcionários.
} 
- Entrevistas abertas ou semiestruturadas. são realizadas em geral durante as visitas de inspeção e podem ser direcionadas a técnicos, à clientela atendida ou à população em geral;

- Questionários: são utilizados com menor frequência, geralmente para levantar dados mais pontuais acerca dos serviços. Podem ser direcionados para gestores, técnicos e funcionários, ou para a clientela e a população em geral;

- Reuniões técnicas, rodas de conversas, atendimentos de grupo: atividades em grupo realizadas com técnicos, atendidos ou a população, visando não só o levantamento de dados, mas também propiciar um espaço de diálogo e de reflexões acerca dos serviços e da política, e em alguns casos, realizar a orientação dos participantes;

- Visitas e reuniões com movimentos sociais ou Conselhos: considerando que a população tem um papel importante na formulação, no acompanhamento e na avaliação das políticas que lhes dizem respeito, busca-se sempre incluir a sociedade civil organizada nos processos de avaliação e acompanhamento das políticas sociais.

Ao final de cada um dos processos avaliativos, o profissional emite um parecer por escrito que irá subsidiar as ações do promotor de justiça. A partir das constatações e das indicações presentes no parecer, o promotor pode solicitar ao gestor público ou ao gestor da entidade privada a adequação do serviço ou a reformulação da política social, da rede, dos fluxos, entre outros.

Importante termos claro que o Ministério Público cumpre a função de ser um órgão de controle dessas políticas. A inserção do psicólogo nesse cenário não foge a esse papel e se constitui num desafio de atuar em um campo novo, comportando riscos e potencialidades que serão discutidos posteriormente.

\section{A psicologia e a avaliação de políticas públicas}

A área de avaliação de políticas públicas há muito se estabeleceu como um campo do conhecimento, com história, arcabouço teórico, metodologias e ferramentas próprias. A avaliação de políticas públicas pode ser definida como um "conjunto de operações racionais, objetivas, sistemáticas e empiricamente fundamentadas que têm por finalidade examinar seus efeitos em relação aos objetivos pré-fixados e às práticas adotadas para atingi-los" (Giovanni, 2015, p. 102). Discussões e conceituações sobre diferentes tipologias, métodos e ciclos de avaliação de políticas ${ }^{3}$, programas e projetos; sobre efetividade, eficiência e eficácia; sobre custo-benefício, entre outros, já fazem parte do vocabulário dos gestores públicos e dos órgãos de controle das políticas sociais.

O mesmo, no entanto, não se pode dizer acerca do conhecimento da psicologia em relação a esse campo - se apenas recentemente as políticas públicas têm sido compreendidas como espaço legítimo para a atuação da nossa profissão, sua inserção nos processos de avaliação dessas políticas é ainda mais recente, sendo que a produção de conhecimento acadêmico sobre o assunto, a partir da ótica da psicologia, é praticamente inexistente.

Dessa maneira, exige-se dos psicólogos que se dedicam a essa prática um diálogo constante com os conhecimentos produzidos por áreas que têm mais intimidade com a temática, como o serviço social, a saúde e a gestão educacional.

Assinalamos que tais campos em que tradicionalmente são realizadas avaliações de políticas públicas têm o olhar mais voltado para os aspectos formais e políticos associados à constituição da própria política, e/ou para a avaliação dos serviços, sua consonância com a legislação, os fluxos, o financiamento, a eficácia e eficiência institucional, a avaliação participativa, entre outros (Frey, 2009; Rico, 2009; Souza, 2006).

A psicologia agrega a esses aspectos o olhar voltado para a subjetividade. A fim de embasar a análise dos efeitos das políticas sociais nos modos de subjetivação, a psicologia tem buscado aportes dados por áreas ligadas à psicologia social de perspectivas críticas como, por exemplo, a psicologia institucional e a psicologia social comunitária.

Entre os autores que têm fornecido subsídios para a análise de políticas públicas pela psicologia, podemos citar os da Análise Institucional (Bleger, Loureau, Lapassade, Baremblitt, Guillon de Albuquerque, entre outros), os que se dedicam à análise de instituições totais (Goffman), aqueles que enfocam as instituições como dispositivos disciplinares

\footnotetext{
${ }^{3}$ Foge ao escopo deste trabalho um aprofundamento sobre esses conceitos, que são cotidianamente utilizados pelos avaliadores de políticas públicas. Para um maior aprofundamento, sugerimos a leitura dos seguintes textos, presentes nas referências deste trabalho: Frey, 2009; Rico, 2009; Souza, 2006; Spink, 2018.
} 
(Foucault, Deleuze e Guatarri), e os teóricos da psicologia sócio-histórica, em especial os ligados à Psicologia Social Comunitária, como Martin-Baró, Lane, Montero, Freitas e Sawaia, entre outros. Esses autores irão - a partir de problematizações, conceitos e pontos de vista teóricos diferentes chamar a atenção para as várias subjetividades e identidades produzidas por esses dispositivos/instituições (Benelli, 2014; Guirado, 2004).

Em comum, eles assinalam a importância de questionarmos acerca de qual subjetividade as instituições (e suas práticas) engendram nas pessoas atendidas, nos próprios efetivadores da política (técnicos e demais funcionários), nas comunidades onde estão inseridas, nos grupos sociais que sentem seus efeitos e na sociedade como um todo, oferecendo subsídios inclusive para problematizar a relação do psicólogo avaliador com a política/instituição avaliada.

Dessa forma, o foco de análise do psicólogo, em sua atuação como avaliador de políticas públicas e de serviços, são os processos de subjetivação produzidos por determinada política e pelas instituições que a consubstanciam, e é essa capacidade de olhar para a subjetividade produzida na e produtora das relações sociais que vai diferenciar sua intervenção da dos demais profissionais (Gonçalves, 2010).

Arretche (2009) distingue três níveis de análise quando se trata de avaliação de políticas:a) o da avaliação política, no qual se analisam os valores, os pressupostos, os fundamentos, o processo decisório e os critérios que levaram à eleição de determinada opção entre as possíveis políticas ; b) o da análise de políticas públicas, no qual se busca compreender a estruturação da política pública como um todo, incluindo seu desenho, sua formulação, implementação, a relação entre os setores que a efetivam, o financiamento, as modalidades de prestação de serviços, enfim, como a política se organiza de forma global; e c) o da avaliação de políticas públicas propriamente dito, que enfoca a relação de causalidade entre determinado programa e os resultados que ele alcança (efetividade, eficácia e eficiência).

Esses três níveis de análise se determinam mutuamente, sendo que sua separação se dá apenas por razões instrumentais. É preciso observar o entrelaçamento entre os valores e pressupostos que sustentam a escolha política, como ela é implementada e quais são de fato seus resultados concretos.

Dos três níveis de avaliação descritos pela autora, o primeiro se refere aos princípios, valores e pressupostos que configuram a política em si, ou seja, inclui a análise de seus fundamentos ontológicos e ético-políticos, bem como dos processos históricos, sociais e culturais que concorreram para sua formulação e sua eleição como política a ser implementada.

Assim, a avaliação política implica em considerar, entre outras coisas, a visão de homem, de mundo e de sociedade por detrás da política adotada (as quais ela recoloca ou naturaliza), o projeto de homem e de justiça que ela contribui para construir ou reforçar, as condições sócio-históricas de sua produção e a correlação de forças que atuaram em sua construção, analisando de que forma esses aspectos informam os processos de subjetivação vigentes na sociedade.

Lembremos que as políticas públicas sociais são ambivalentes, posto que de um lado procuram minorar os efeitos da "Questão Social", contribuindo para a naturalização das desigualdades sociais e para a adaptação dos trabalhadores a situações de exploração, mas por outro são fruto de luta da classe trabalhadora por condições de vida mais digna (Oliveira, 2017; Oliveira \& Costa, 2018; Yamamoto \& Oliveira, 2010).

É preciso compreender como a política em análise atua para reforçar cada uma dessas duas direções quais dos seus elementos contribuem para garantir de fato os interesses, direitos e necessidades da classe trabalhadora e da população em geral, e quais atuam no sentido de reforçar a normatização, a massificação, a homogeneização dos indivíduos e a adaptação social (Gonçalves, 2010; Miron \& Guareschi, 2017).

O mesmo pode ser dito do segundo nível de análise, que trata das formas concretas como a política pública se estrutura: desenho, formulação, implementação, rede, fluxos, legislação/regulamentação, financiamento, recursos humanos, entre outros.

Analisar a forma concreta como a política se constitui é essencial para avaliar não só sua qualidade, mas o sentido em que a política opera. Dessa forma, a garantia dos parâmetros previstos nas leis, normativas e recomendações técnicas é imprescindível para que a política de fato atinja os objetivos a que explicitamente se propõe, em vez de produzir efeitos no sentido oposto.

Reitera-se, no entanto, que essa avaliação não deve restringir-se somente à execução da política, às modalidades e às formas como os serviços são ofertados, mas deve considerar os processos sociais e políticos associados à implementação da política social, dos programas e dos projetos, posto que esses são essenciais à sua conformação (Spink, 2018). 
Quanto à avaliação dos serviços em si, tendo-se em vista que eles se configuram como uma materialização de determinada política, deve-se considerar as condições objetivas concretas das instituições e seus aspectos funcionais, o cotidiano institucional, as relações (intrainstitucionais e interinstitucionais) que são estabelecidas, as normas ditas e não ditas que regulamentam a prática institucional, a relação com a clientela e com a comunidade.

Assim, mais do que analisar dada instituição em seu funcionamento concreto, a psicologia contribui para evidenciar que ela é uma materialização de uma dada política, que é informada por e reproduz determinada visão de homem e de mundo, chamando a atenção para a necessidade de se observar a subjetividade que é construída nos processos sociais e que, ao mesmo tempo, dialeticamente, os constitui (CFP, 2011).

É preciso observar como as políticas sociais e as instituições que as consubstanciam, com suas normas e regras, produzem e legitimam determinados valores, lugares sociais e relações entre as pessoas - são produtoras de identidades e modos de subjetivação.

A "dimensão subjetiva dos fenômenos sociais" (Gonçalves, 2010, p. 64) diz respeito à produção de formas de ser e de estar no mundo, de se relacionar com outros, com a comunidade e com a sociedade fomentadas, nesse caso específico, pelas relações com as políticas sociais. Gonçalves (2010), citando Paugam (2003), relata a forma como a clientela das políticas estatais passa a se relacionar com a sociedade a partir do serviço e dos profissionais que lhe prestam assistência. Ser usuário de uma determinada política produz uma identidade e um lugar social, assim como não ter acesso à política ou dela não necessitar também contribui para produzir um outro lugar social e reforçar determinada identidade.

A forma como as políticas públicas operam produz valores, legitimações e naturalizações de determinadas visões de mundo e de lugares sociais, contribuindo para produzir modos de subjetivação e marcadores sociais específicos para usuários e não usuários dessas políticas públicas.

A prática assistencialista que subsiste em vários municípios e serviços, largamente identificada nas avaliações realizadas pelos psicólogos do MPSP, reproduz e reforça uma concepção de minoridade e subalternidade do indivíduo, que é alvo passivo das intervenções técnicas decididas pelos profissionais, que deteriam o conhecimento acerca do que é melhor para aqueles usuários.

Já as políticas que partem de uma visão do indivíduo como sujeito de direitos, compreendem-nos como iguais, como detentores de um conhecimento, de potencialidade e de capacidade de autonomia e de decisão. Percebe-se, assim, que essas formas opostas de intervenção engendram formas também opostas de subjetividade.

A participação ou não da clientela atendida e da comunidade no processo de formulação, implementação e acompanhamento das políticas que são pretensamente construídas para atender às suas necessidades, também é um indicativo importante de quais modos de subjetivação a política contribui para produzir.

Gonçalves (2010, p. 64) pontua que a participação ou não dos atendidos na formulação da política e dos serviços evidencia a concepção de sujeito que informa aquela política. Segundo a autora, "indivíduos que recebem benefícios, sem nenhuma possibilidade de decidir sobre as características de tais ações, são negados também como sujeitos. Isso será vivenciado e produzirá efeitos de subjetivação que terão seus desdobramentos".

Cabe ainda um destaque para a necessidade de olhar a subjetividade produzida nos próprios profissionais que executam as políticas sociais: a falta de retaguarda institucional, os limites impostos pela política para a prática profissional, o cerceamento da liberdade técnica, as ingerências cotidianas, a falta de condições de trabalho, entre outros, levam a um sofrimento psíquico, a uma sensação de incapacidade, de impotência e de menos valia (Macedo \& Dimenstein, 2012), que impactam a subjetividade desses sujeitos.

A eventual precarização dos serviços (da remuneração, carga horária, das condições de trabalho, falta de estrutura física, falta de material para o desenvolvimento do trabalho, fragilidade do vínculo empregatício, burocracia, ausência de capacitação, pouca autonomia técnica) identificada por Macedo e Dimenstein (2012), deve ser compreendida não como uma casualidade, mas como uma opção da política pública, haja vista que a alocação de esforços e de recursos é também um reflexo das decisões políticas e revela a real política pública social adotada pelo gestor (Spink, 2018).

É preciso que a psicologia contribua com a construção e efetivação de políticas sociais que promovam 
o fortalecimento das pessoas e das comunidades atendidas, nas quais a clientela seja de fato contemplada em suas necessidades, cuja relação com as pessoas atendidas seja dialógica, de respeito a suas potencialidades, de fomento do pensamento crítico e da autodeterminação (dos indivíduos e da comunidade), para que seja superado o sentimento de fatalismo e de subserviência tão presente em nossa sociedade, reforçado por muitas políticas sociais.

Assim, frisa-se na prática avaliativa a importância de realizar avaliações que superem uma análise meramente funcional da instituição e da política, mas que tenham como objeto a compreensão da subjetividade que aquela instituição ou política engendram/produzem (CFP, 2011).

\section{Os desafios e as potencialidades da psicologia na avaliação de políticas públicas sociais}

As políticas públicas sociais podem ser consideradas como ". . . promessas e possibilidades que ainda não se cumpriram em sua execução" (Cordeiro, Svartman \& Souza, 2018, p. 9), e a psicologia tem sido chamada a contribuir para que sua implementação seja efetiva e para que elas de fato respondam às necessidades da população atendida.

No entanto, a inserção do psicólogo em processos de avaliação de serviços e políticas públicas, posto que recente, se constitui num desafio de atuar em um campo novo, com todos os riscos e as potencialidades que isso representa.

Um dos principais desafios que se apresenta para o psicólogo diz respeito à falta de formação para as políticas públicas (Cordeiro et al., 2018; Freitas, 2015; Silva \& Carvalhaes, 2016), e mais ainda para a avaliação dessas políticas. Muitos profissionais tiveram que aprender o trabalho a ser desenvolvido concomitante a sua realização, o que se torna um obstáculo ainda maior se considerarmos a ausência de referencial teórico da psicologia nessa área, de tal forma que esses profissionais precisaram construir seus próprios referenciais teóricos e de atuação prática.

A ausência de uma formação que dê subsídios para uma atuação nas políticas públicas em geral tem levado os profissionais a reproduzirem paradigmas e ontologias tradicionais, fazendo transposições acríticas de modelos clínicos a situações complexas, histórico e socialmente condicionadas (Cordeiro et al., 2018; Miron \& Guareschi, 2017; Silva \& Carvalhaes, 2016). No caso da avaliação de políticas públicas sociais, há um risco de os processos avaliativos centrarem-se em aspectos individuais e pontuais dessas políticas e de reproduzirem uma postura de responsabilização e culpabilização individuais seja dos técnicos, seja dos atendidos - pela falta de eficácia e eficiência das políticas.

Ao reproduzir um paradigma que desconsidera as subjetividades como socialmente engendradas, o psicólogo avaliador corre o risco de psicologizar questões que são condicionadas sócio-histórica e politicamente, contribuindo assim com os processos de submissão, enquadramento e de normatização social. Com isso, favorece a subsistência e a manutenção de políticas sociais que fomentam a adaptação dos atendidos a uma ordem social excludente e que reforçam a reprodução de relações alienadas, elitistas e produtoras de sofrimento psíquico (Oliveira \& Brito, 2013; Silva \& Carvalhaes, 2016; Yamamoto \& Oliveira, 2010).

Ademais, no caso da atuação com avaliação de políticas públicas em uma instituição cuja atividade-fim ${ }^{4}$ é subsidiária ao Direito ou que tem como função o controle da política, há o risco de uma reprodução de um legalismo, com um olhar sobremaneira voltado para as normas e legislações e para seu cumprimento (Oliveira \& Brito, 2013), e que na prática desconsidera a subjetividade que atravessa a política, as instituições e as pessoas que as compõem.

Nesse sentido, uma das principais potencialidades da psicologia no processo de avaliação de políticas públicas sociais é a de recuperar o sujeito por trás da política ou das práticas institucionais. A fim de alcançar esse intento, o psicólogo deve adotar uma postura que fomente uma perspectiva dialógica e crítica (Cordeiro et al., 2018), seja com a população, seja com os técnicos dos serviços, seja com os operadores das políticas, haja vista que nossa atuação como avaliadores também interfere nos processos de produção de subjetividades.

A atuação da psicologia na avaliação de políticas públicas sociais concorre para a transformação social, uma vez que produz impactos objetivos e subjetivos. Concretamente, a avaliação da política social por

\footnotetext{
4 "Atividade-fim" diz respeito às atividades diretamente associadas com o objetivo principal de determinada instituição ou empresa, enquanto "atividade-meio" diz respeito às atividades realizadas em caráter subsidiário à principal.
} 
parte da psicologia contribui para o aprimoramento do serviço ofertado à sociedade, de tal forma que ela passe a atender os interesses objetivos da população, em vez de servir como mecanismo de adaptação e de apaziguamento dos conflitos sociais.

Com isso, o psicólogo pode contribuir para que as políticas públicas sociais se configurem como espaços de promoção de autonomia e de fortalecimento da população atendida, de maneira que os serviços promovam processos de subjetivação emancipatórios em vez de contribuírem com a construção de identidades subservientes, impotentes e conformadas.

Uma atuação ética e politicamente comprometida com a transformação social é essencial para desconstruir o olhar normatizador, adaptador e homogeneizador que em geral informa os processos avaliativos, recuperando os seres humanos e os diferentes processos de subjetivação que existem por trás não só da política, mas do próprio procedimento de avaliação.

Nessa perspectiva, o processo de avaliação das políticas públicas e dos serviços é compreendido como interventivo, isto é, devemos ter a dimensão de que a função da avaliação, por parte do psicólogo, além de garantir a qualidade dos serviços ofertados, é a de que o próprio processo se configure como um espaço de produção de saúde mental, de autonomia, de desnaturalização e de quebra dos papéis sociais reificados e reprodutores de sofrimento e alienação.

Evidencia-se, com isso, que ao realizar a avaliação de uma política ou serviço, a atuação do psicólogo é parte ativa do processo de produção de subjetividades engendrado pela política, de tal forma que sua intervenção como avaliador pode colaborar para a produção subjetividades reificadas ou emancipadas.

Nesse sentido, ao avaliar uma política pública social, o psicólogo precisa se reconhecer como agente político (Silva \& Carvalhaes, 2016), pois sua atuação produz transformações concretas na forma como aquela política é implementada, o que por sua vez resulta em produção de identidades, lugares sociais e formas de ser e de existir no mundo.

Em suma, apostamos na potência da contribuição da psicologia com o campo de avaliação de políticas públicas, desde que esta parta de uma concepção que não cinda os processos de subjetivação dos processos sociais, assumindo uma posição ético-política comprometida com a construção de políticas sociais que de fato atendam às necessidades de nosso povo e que contribuam com a transformação individual, coletiva e social.

\section{Referências}

Arretche, M. T. S. (2009). Tendências no estudo sobre avaliação. In E. M. Rico (Org.), Avaliação de políticas públicas: Uma questão em debate ( $6^{\text {a }}$ ed., pp. 29-40). Cortez.

Benelli, S. J. (2014). A lógica da internação: Instituições totais e disciplinares (des)educativas. Unesp. http://books. scielo.org/id/74z7q

Benevides, R. (2005). A psicologia e o Sistema Único de Saúde: Quais interfaces? Psicologia \& Sociedade, 17(2), 21-25. http://doi.org/10.1590/S0102-71822005000200004

Cordeiro, M. P., Svartman, B., \& Souza, L. V. (2018). Psicologia na Assistência Social: Um campo de saberes e práticas. Instituto de Psicologia da USP. www.livrosabertos.sibi.usp.br/portaldelivrosUSP/catalog/ download/212/191/890-1?inline=1

Conselho Federal de Psicologia. (2011). Como os psicólogos e as psicólogas podem contribuir para avançar o Sistema Único de Assistência Social (SUAS): Informações para gestores e gestoras. CREPOP. http:/ / crepop.pol.org.br/novo/ wp-content/uploads/2011/12/GestoresSuasfinanl-corrigido.pdf

Conselho Federal de Psicologia. (2019). Referências Técnicas para a atuação de psicólogas (os) em questões relativas à terra. CFP.

Cruz, L. R., \& Guareschi, N. M. F. (2012). A constituição da assistência social como política pública: interrogações à psicologia. In: L. R. Cruz, N. M. F. Guareschi (Orgs.), Políticas públicas e assistência social:Diálogo com as práticas psicológicas (pp. 13-40). Vozes.

Figueiredo, G. C. (2019). O trabalho do psicólogo no Ministério Público de São Paulo - apontamentos iniciais. In B. R. Souza, C. F. Ferreira, C. A. Silva, J. A. H. Fialho, L. G. O. Pedott, L. D. F. L Cabral, L. R. Paneghini \& P. D. V. 
Bergamin (Orgs.), NAT em Movimento: Práticas do Núcleo de Assessoria Técnica Psicossocial (pp. 23-36). MPSP. www.mpsp.mp.br/portal/page/portal/CAO\%20Tutela/livro_nat

Freitas, M. F. Q. (2015). Políticas Públicas e Psicologia Social Comunitária: interfaces e desafios. In D. Beatriz (Org.), Práticas do psicólogo em políticas públicas (pp. 29-42). Juruá.

Frey, K. (2009). Políticas públicas: Um debate conceitual e reflexões referentes à praticada análise de políticas públicas no Brasil. Revista Planejamento e Políticas Públicas, 21, 211-259. http://www.ipea.gov.br/ppp/index. $\mathrm{php} / \mathrm{PPP} /$ article/view/89/158

Giovanni, G. D. (2015). Avaliação. In G. D. Giovanni, \& M. A. Nogueira, Dicionário de Políticas Públicas (2ª ed., pp. 102-103). Editora da Unesp/Fundap.s

Giovanni, G. D., \& Nogueira, M. A. (2015). Dicionário de Políticas Públicas (2ª ed.). Editora da Unesp/Fundap.

Gonçalves, M. G. M. (2010). Psicologia, subjetividade e políticas públicas. Cortez.

Guirado, M. (2004). Instituições e relações afetivas: O vínculo com o abandono. Casa do Psicólogo.

Macedo, J. P. S., \& Dimenstein, M. (2012). O trabalho dos psicólogos nas políticas sociais no Brasil. Avances en Psicologia Latinamericana, 30(1), 189-199. http://www.scielo.org.co/scielo. php?script=sci_arttext\&pid=S1794-47242012000100015

Ministério Público do Estado de São Paulo, Procuradoria-Geral de Justiça. (13 jan. 2012). Ato Normativo no 724 , de 13 de janeiro de 2012. Institui, no Ministério Público do Estado de São Paulo, o Núcleo de Assessoria Técnica Psicossocial - NAT. Diário Oficial: Poder Executivo, 122(10), 49. http://biblioteca.mpsp.mp.br/PHL_IMG/ Atos/724.pdf

Miron, A. X., \& Guareschi, N. M. F. (2017). Compromisso social da Psicologia e Sistema Único de Assistência Social: Possíveis articulações. Psicologia:CiênciaeProfissão, 37(2),349-362.https://doi.org/10.1590/1982-3703000952014

Oliveira, C. F. B., \& Brito, L. M. T. (2013). Judicialização da vida na contemporaneidade. Psicologia: Ciência e Profissão, 33(spe), 78-89. http://www.scielo.br/scielo.php?script=sci_arttext\&pi=S1414-98932013000500009\&lng=en\&nrm=iso

Oliveira, I. F. (2017). A assistência social em tempos de capital barbárie. In E. Rasera, M. S. Pereira, D. Galindo (Orgs.), Democracia participativa, estado e laicidade: Psicologia social e enfrentamentos em tempos de exceção (pp. 98-107). ABRAPSO.

Oliveira, I. F., \& K. F. O. Amorim, (2012). Psicologia e Política social: O trato da pobreza como "sujeito psicológico". Psicologia Argumento, 30(70), 559-566. https://periodicos.pucpr.br/index.php/psicologiaargumento/article/ view/20519

Oliveira, I. F, \& A. L. F. Costa, (2018). Psicologia e política social: história e debate. In M .P. Cordeiro, B. Svartman \& L. V. Souza, Psicologia na Assistência Social: Um campo de saberes e práticas (pp. 32-44). Instituto de Psicologia da USP. www.livrosabertos.sibi.usp.br/portaldelivrosUSP/catalog/download/212/191/890-1?inline=1

Ortuso, A., \& G. D. Giovanni (2015). Política social. In G. D. Giovanni \& M. A. Nogueira, Dicionário de Políticas Públicas (2a ed., pp. 765-766). Editora da Unesp/Fundap.

Rico, E. M. (Org.). (2009). Avaliação de políticas públicas: Uma questão em debate (6 ed.) Cortez.

Silva, R. B., \& Carvalhaes, F. F. (2016). Psicologia e políticas públicas: Impasses e reinvenções. Psicologia \& Sociedade, 28(2), 247-256. http://doi.org/10.1590/1807-03102016v28n2p247

Souza, C. (2006). Políticas públicas: Uma revisão da literatura. Sociologias, 8(16), 20-45. www.scielo.br/pdf/soc/ n16/a03n16

Spink, P. K. (2018). Psicologia e políticas públicas. In M. P. Cordeiro, B. Svartman, L.V. Souza, Psicologia na Assistência Social: Um campo de saberes e práticas (pp. 13-31). Instituto de Psicologia da USP. www.livrosabertos.sibi.usp.br/ portaldelivrosUSP/catalog/download/212/191/890-1?inline=1

Yamamoto, O. H. (2009). Questão Social e políticas públicas: Revendo o compromisso da Psicologia. In A. M. M. Bock (Org.), Psicologia e o compromisso social (pp. 37-54). Cortez.

Yamamoto, O. H., \& Oliveira, I. F. (2010). Política social e psicologia. Psicologia: Teoria e Pesquisa, 26(spe), 9-24. http://doi.org/10.1590/S0102-37722010000500002 


\section{Gislayne Cristina Figueiredo}

Graduada, mestra e doutora em Psicologia pela Universidade de São Paulo (USP), Ribeirão Preto - SP, Brasil. Professora titular do curso de psicologia da Universidade Federal de Mato Grosso (UFMT), Cuiabá - MT, Brasil. Atua principalmente nos seguintes temas: psicologia social, políticas públicas, exclusão social e assentamentos rurais.

E-mail: gislaynecf@hotmail.com

(1) https://orcid.org/0000-0001-6656-2266

Endereço para envio de correspondência:

Departamento de Psicologia, Instituto de Educação. Av. Fernando Corrêa da Costa, 2367, Bairro Boa Esperança. CEP: 78060-900. Cuiabá - MT. Brasil.

Recebido 07/01/2020

Aceito 30/03/2021

Received $01 / 07 / 2020$

Approved 03/30/2021

Recibido 07/01/2020

Aceptado 30/03/2021

Como citar: Figueiredo, G. C. (2022). Avaliação de políticas públicas: Desafios e potencialidades para a psicologia. Psicologia: Ciência e Profissão, 42, 1-12. https:// doi.org/10.1590/1982-3703003232807

How to cite: Figueiredo, G. C. (2022). Evaluation of public policies: challenges and potentialities for psychology. Psicologia: Ciência e Profissão, 42, 1-12. https:// doi.org/10.1590/1982-3703003232807

Cómo citar: Figueiredo, G. C. (2022). Evaluación de políticas publicas: Desafíos y potencialidades para la psicología. Psicologia: Ciência e Profissão, 42, 1-12. https://doi.org/10.1590/1982-3703003232807 